\title{
A SENSITIVE ANALYTICAL (RP-HPLC-PDA, UV/VIS) METHOD FOR THE DETERMINATION OF NEWLY SYNTHESIZED N-ISONICOTINOYL-N'-(3-FLUOROBENZAL)HYDRAZONE (SH2) IN AQUEOUS PHASE
}

\author{
ZVEZDELINA YANEVA ${ }^{\mathrm{a}^{*}}$, NEDYALKA GEORGIEVA
}

\begin{abstract}
The purpose of the present study was to develop a simple, rapid and reproducible analytical method for the determination of $\mathrm{N}$ isonicotynoyl-N'-(3-fluorobenzal)hydrazone ( $\mathrm{SH} 2)$ - a synthesized by us halogenated isoniazid derivative with high tuberculostatic activity, in aqueous phase, on the basis of RP-HPLC-PDA and UVIVIS spectrophotometric investigations. Despite of the high linearity $\left(R^{2}\right.$ 0.9984) of the UVIVIS spectrophotometric method applied, the significantly higher LOQ and LOD values indicated its unsuitability for detection and quantification of low $\mathrm{N}$ isonicotynoyl-N'-(3-fluorobenzal)hydrazone concentrations $(<10 \mu \mathrm{g} / \mathrm{mL})$. The proposed RP-HPLC-PDA method with mobile phase ACN/phosphate buffer $(60: 40, \mathrm{v} / \mathrm{v})$ offered short retention time (3.1 min), high precision (RSD $3.50 \%)$ and linearity $\left(R^{2} 0.9898\right)$. It characterized with satisfactory LOD $(0.346 \mu \mathrm{g} / \mathrm{mL})$ and LOQ $(1.05 \mu \mathrm{g} / \mathrm{mL})$ values and allowed the qualitative detection of $\mathrm{SH} 2 \mathrm{E} / \mathrm{Z}$-isomer.
\end{abstract}

Keywords: N-isonicotynoyl-N'-(3-fluorobenzal)hydrazone, RP-HPLC-PDA, UVNIS, aqueous phase

\section{INTRODUCTION}

The rise in drug-resistant strains of Mycobacterium tuberculosis is a major threat to human health and highlights the need for new therapeutic strategies [1].

Despite its strong antibacterial effect, sometimes isoniazid (rimifon, INH), a widely used medication (xenobiotic) with a confirmed tuberculostatic activity, is proved to be ineffective due to the rapid appearance of drug resistance of

\footnotetext{
a Chemistry Unit, Department of Pharmacology, Animal Physiology and Physiological Chemistry, Faculty of Veterinary Medicine, Trakia University, Students Campus, 6000 Stara Zagora, Bulgaria.

*Corresponding author: z.yaneva@abv.bg
} 
tuberculosis bacteria [2]. These two problems - the toxicity and the resistance, motivate the necessity of synthesis of new tuberculostatics: more active, overcoming the resistance and with a lower toxicity. Particularly good results in the study of antituberculosis activity and toxicity are obtained for the family of isonicotinoyl hydrazones - structural analogues of isoniazid $[1,3,4]$. The blockade of the active hydrazide group $\left(-\mathrm{HNNH}_{2}\right)$ results in a significant decrease in the toxicity of isonicotinoyl hydrazones $v s$ that of INH [5-7].

In experiments of ours, we synthesized and evaluated the tuberculostatic activity of new xenobiotics, not described in the literature - structural analogues of INH [8] against a standard Mycobacterium tuberculosis H37Rv-London strain, that is highly virulent, causes a generalized tuberculosis and is used in international studies. The results of the screening showed that all newly synthesized xenobiotics had a highly inhibiting activity against tuberculosis bacteria [9].

The study of Potuckova et al. (2014) highlighted important structureactivity relationships and provides insights into the further development of arylhydrazone iron chelators with more potent and selective anti-neoplastic effects [10]. Analysis of new chelators were performed using an Ascentis C18 chromatographic column $(1063 \mathrm{~mm}, 3 \mathrm{~mm})$ protected with a guard column with the same sorbent (Sigma-Aldrich). The mobile phase was composed of $1 \mathrm{mM}$ EDTA in $5 \mathrm{mM}$ phosphate buffer and methanol in different ratios. The column oven was set at $25^{\circ} \mathrm{C}$ and the autosampler at $5^{\circ} \mathrm{C}$. A flow rate of $0.3 \mathrm{~mL} / \mathrm{min}$ and injection volume of $20 \mathrm{~mL}$ were used. The linearity, precision and accuracy of the methods were examined by the analysis of plasma samples spiked with different amounts of the chelators. Selectivity was confirmed by an analysis of blank plasma samples. All evaluated parameters reached acceptable values [10].

It is accepted by some scientists that UV/VIS spectrophotometric methods are less time-consuming in terms of preparation and analysis of samples and are more cost effective than chromatographic methods. A new analytical method for the quantification of isonicotinoyl lactosyl hydrazone (INH-Lac) in oral solid dosage forms by UV-spectrophotometry was developed and validated by Cordoba-Diaz et al. (2009) [11]. The influence of several direct compression excipients on the specificity of the proposed analytical method were evaluated. The applied methodology showed a good repeatability as well as good accuracy. The results obtained from the assay of isoniazid tablets demonstrated that the proposed method constitutes a clear alternative to chromatographic methods and to the official titration method. It would be of interest for the routine quality control of oral dosage forms containing isoniazid and lactose and for stability studies [11]. In the study of Georgieva and Yaneva (2015) subjected to encapsulation of rimifon on natural and acid-modified zeolites, rimifon concentrations before and after encapsulation were determined by a UV/VIS spectrophotometric method. The standard curve was linear over the range of the tested concentrations [12]. A RP-HPLC-PDA analytical 
methodology for the determination of the veterinary antibiotic tylosine in aqueous phase, which characterized with short analysis time, high precision, high linearity and satisfactory LOD and LOQ values, was developed [13].

Previous investigations of the scientific team proved the superoxide scavenging, radical scavenging and tuberculostatic activities of substituted isonicotynoylhydrazones $[9,14]$. However, no analytical methods for the determination of halogenated isonicotynoylhydrazones in aqueous medium have been reported so far, which provoked the present research.

The aim of this study was to develop a simple, rapid and reproducible analytical method for the determination of $\mathrm{N}$-isonicotynoyl- $\mathrm{N}^{\prime}$ (3-fluorobenzal)hydrazone - a synthesized by the authors halogenated isoniazid derivative with high tuberculostatic activity, in aqueous phase, on the basis of RP-HPLC-PDA and UV/VIS spectrophotometric investigations.

\section{RESULTS AND DISCUSSION}

\section{UV/VIS spectrophotometric analyses}

The UV/VIS spectra of $\mathrm{SH} 2$ in acidic aqueous solutions $(\mathrm{pH} 2.4)$ (Fig. 1) displayed maximum absorbance peaks in the UV region at $\lambda 250 \mathrm{~nm}$ for the entire concentration range $10-100 \mu \mathrm{g} / \mathrm{mL}$. The $\mathrm{pH}$ of all solutions was adjusted to $\mathrm{pH} 2.4$.

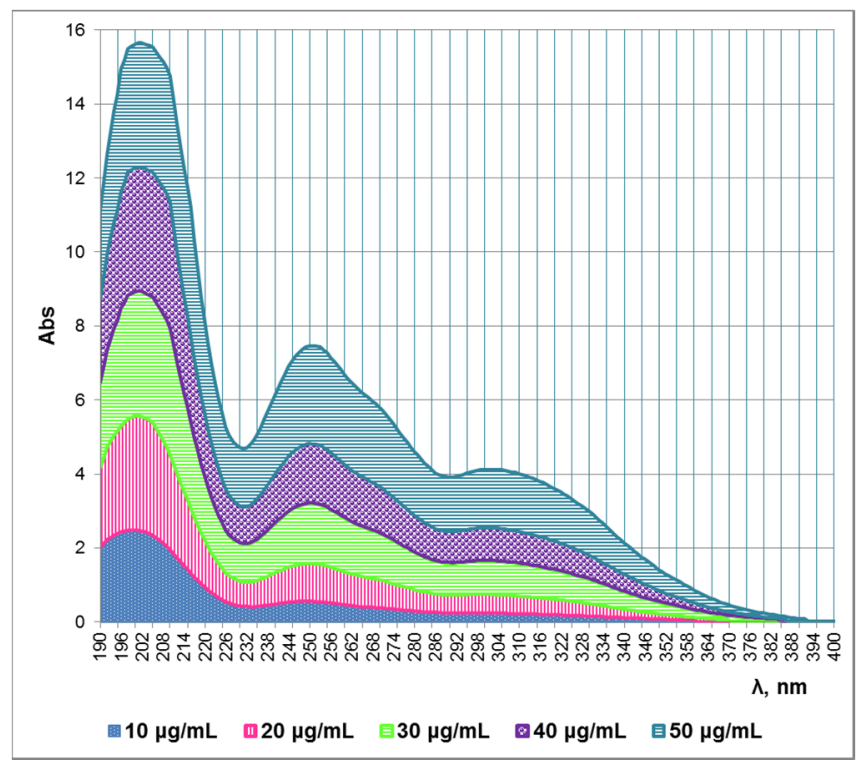

Figure 1. UV/VIS spectra of SH2. 
The obtained standard curve for $\mathrm{SH} 2$ (Fig. 2) was linear over the tested range of initial concentrations $\mathrm{C}_{\circ} 10-100 \mu \mathrm{g} / \mathrm{mL}$.

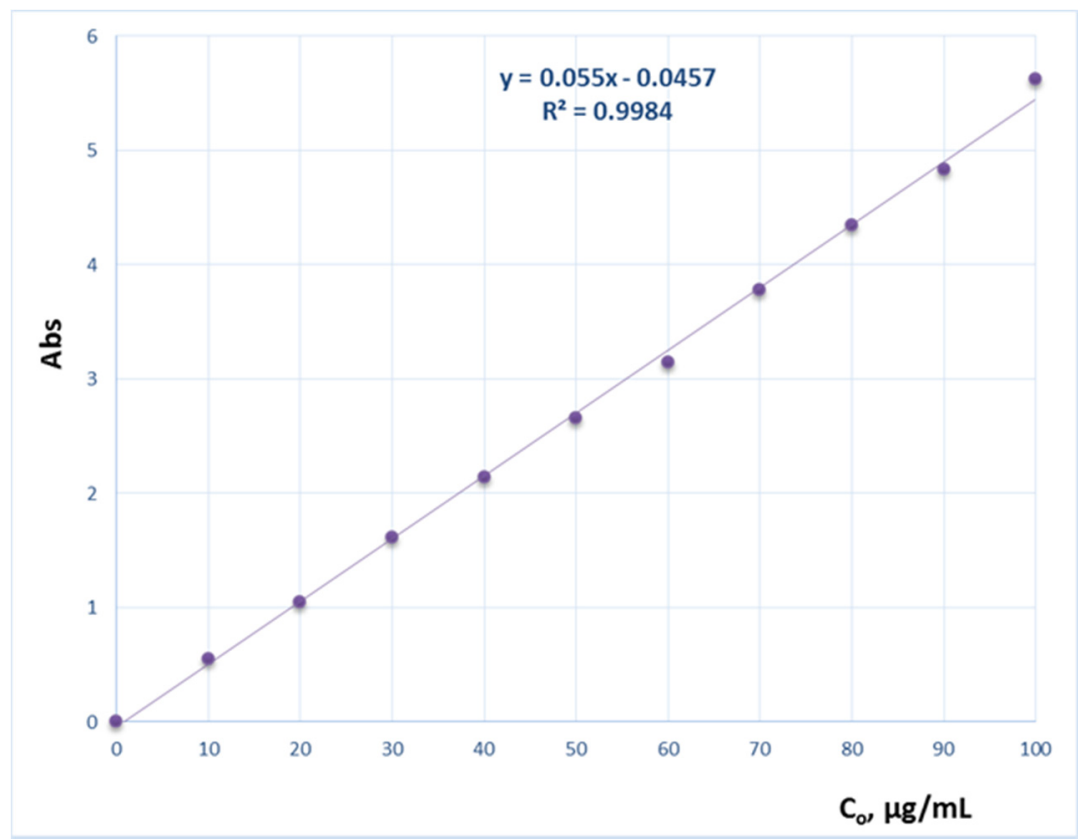

Figure 2. UV/VIS calibration curve of $\mathrm{SH} 2$ at $\lambda 250 \mathrm{~nm}$.

The obtained linear equation (Eq. 1) characterized with a slope $a=$ 0.055 and an intercept $b=-0.0457$.

$$
y=0.055 . x-0.0457
$$

The high value of the calculated correlation coefficient $-R^{2} 0.9984$, and the well resolved UV absorption peaks of the heterocyclic compound proved the applicability of this method for determination of $\mathrm{SH} 2$ concentrations in aqueous medium in the range $C_{0} 10-100 \mu \mathrm{g} / \mathrm{mL}$.

\section{HPLC method development}

The development and optimization of a sensitive and rapid HPLC method for $\mathrm{SH} 2$ determination in aqueous phase included the performance of several preliminary experiments testing different HPLC conditions: mobile phases, temperatures and wavelengths. 


\section{HPLC Method I}

The first experimental series were conducted with ten $\mathrm{SH} 2$ standard solutions with concentrations $10,20,30,40,50,60,70,80,90$ and 100 $\mu \mathrm{g} / \mathrm{mL}$. The used mobile phase consisted of phosphate buffer $(\mathrm{pH} 5.0)$ and methanol $(90: 10, v / v)$. Optimal performance was obtained at a flowrate 0.8 $\mathrm{mL} / \mathrm{min}$. The effect of temperature on the separation process was studied in the range $18-30^{\circ} \mathrm{C}$. Satisfactory peak resolution and optimum analyses time were established at $30^{\circ} \mathrm{C}$, at wavelength $\lambda 254 \mathrm{~nm}$. SH2 was successfully detected within $3.35 \mathrm{~min}$ in the solution with $\mathrm{C}_{0} 10 \mu \mathrm{g} / \mathrm{mL}$ (Fig. 3). However a mode of reduction of the detection time from $3.35 \mathrm{~min}$ to $3.1 \mathrm{~min}$ with an increase in the initial $\mathrm{SH} 2$ concentration within the range $\mathrm{C}_{0} 10-100 \mu \mathrm{g} / \mathrm{mL}$ was observed (Fig. 3). The base lines of the chromatograms characterized with signal noise in the time range 1.9-2.5 min and unstable base line, especially in the lower concentration range. Besides, the characteristic peak for $C_{o} 100 \mu \mathrm{g} / \mathrm{mL}$ contained a curvature, which could affect the accuracy of the quantitative determination.

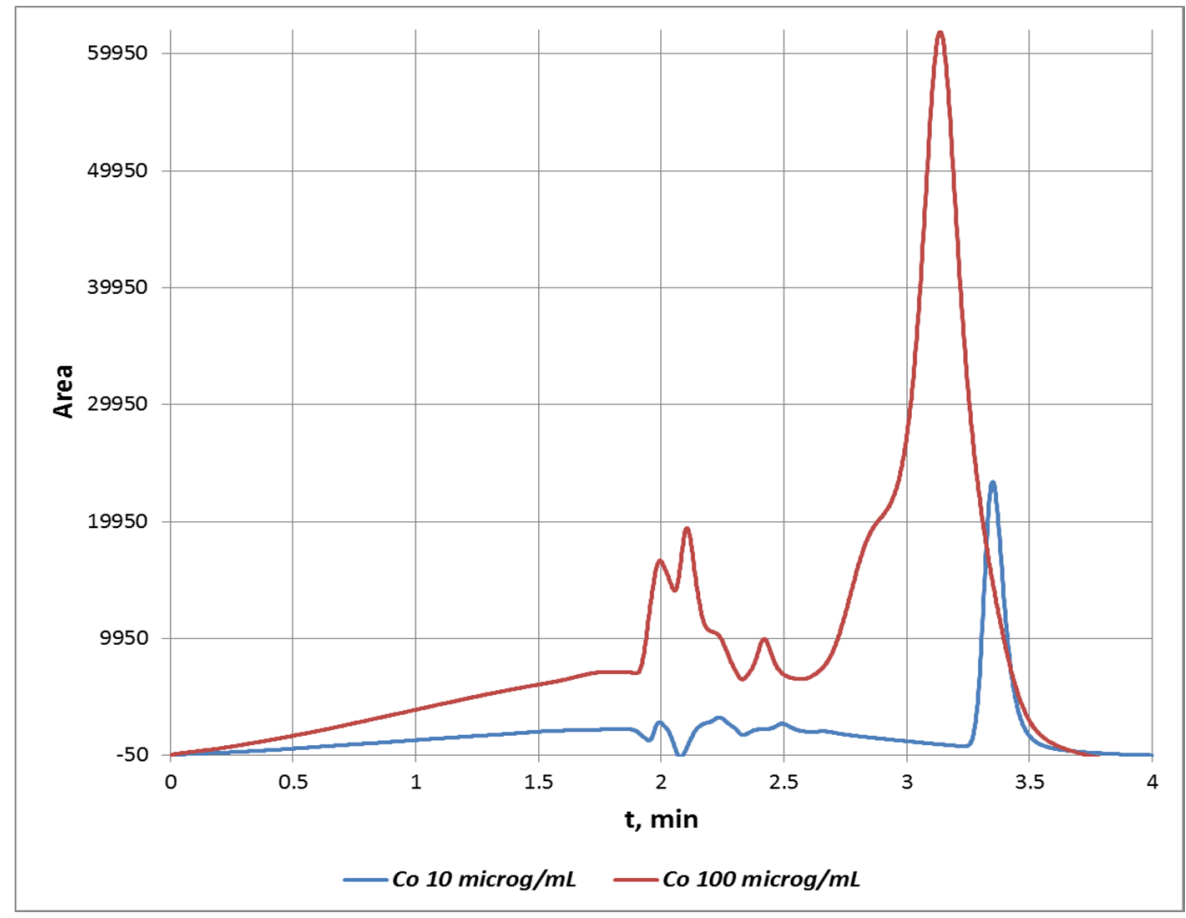

Figure 3. HPLC spectra of $\mathrm{N}$-isonicotynoyl- $\mathrm{N}^{\prime}$-(3-fluorobenzal)hydrazone at $\lambda 254 \mathrm{~nm}$, mobile phase: phosphate buffer $(\mathrm{pH} 5.0) /$ methanol $(90: 10, \mathrm{v} / \mathrm{v})$. 
The standard calibration curve based on the spectral peak areas is presented in Fig. 4.

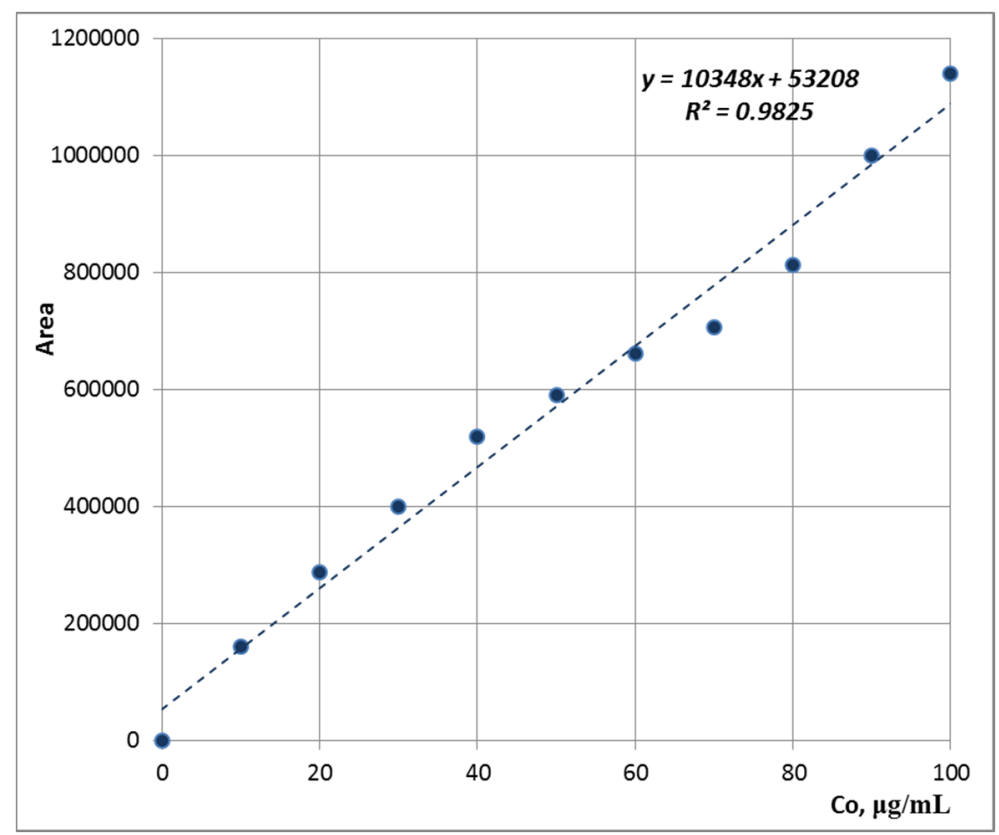

Figure 4. HPLC calibration curve of $\mathrm{N}$-isonicotynoyl-N'-(3-fluorobenzal)hydrazone at $\lambda 254 \mathrm{~nm}$ (mobile phase: phosphate buffer $(\mathrm{pH} 5.0) /$ methanol $(90: 10, \mathrm{v} / \mathrm{v})$.

It characterized with a reasonable correlation coefficient $\mathrm{R}^{2} 0.9825$ and the following linear equation (2):

$$
y=10348 \cdot x+53208
$$

\section{HPLC Method II}

The second experimental series were conducted with the same ten $\mathrm{SH} 2$ standard solutions in the concentration range $\mathrm{C}_{\circ} 10-100 \mu \mathrm{g} / \mathrm{mL}$. The used mobile phase consisted of $A C N$ and $\mathrm{H}_{3} \mathrm{PO}_{4}(0.1 \mathrm{M})(60: 40$, v/v). Optimal performance was obtained at a flowrate $0.8 \mathrm{~mL} / \mathrm{min}$. The effect of temperature on the separation process was studied in the range $18-30^{\circ} \mathrm{C}$. Satisfactory peak resolution and optimum analyses time were established at $30^{\circ} \mathrm{C}$, at wavelength $\lambda 300 \mathrm{~nm}$. SH2 was successfully detected within 3.1 min (Fig. 5). 


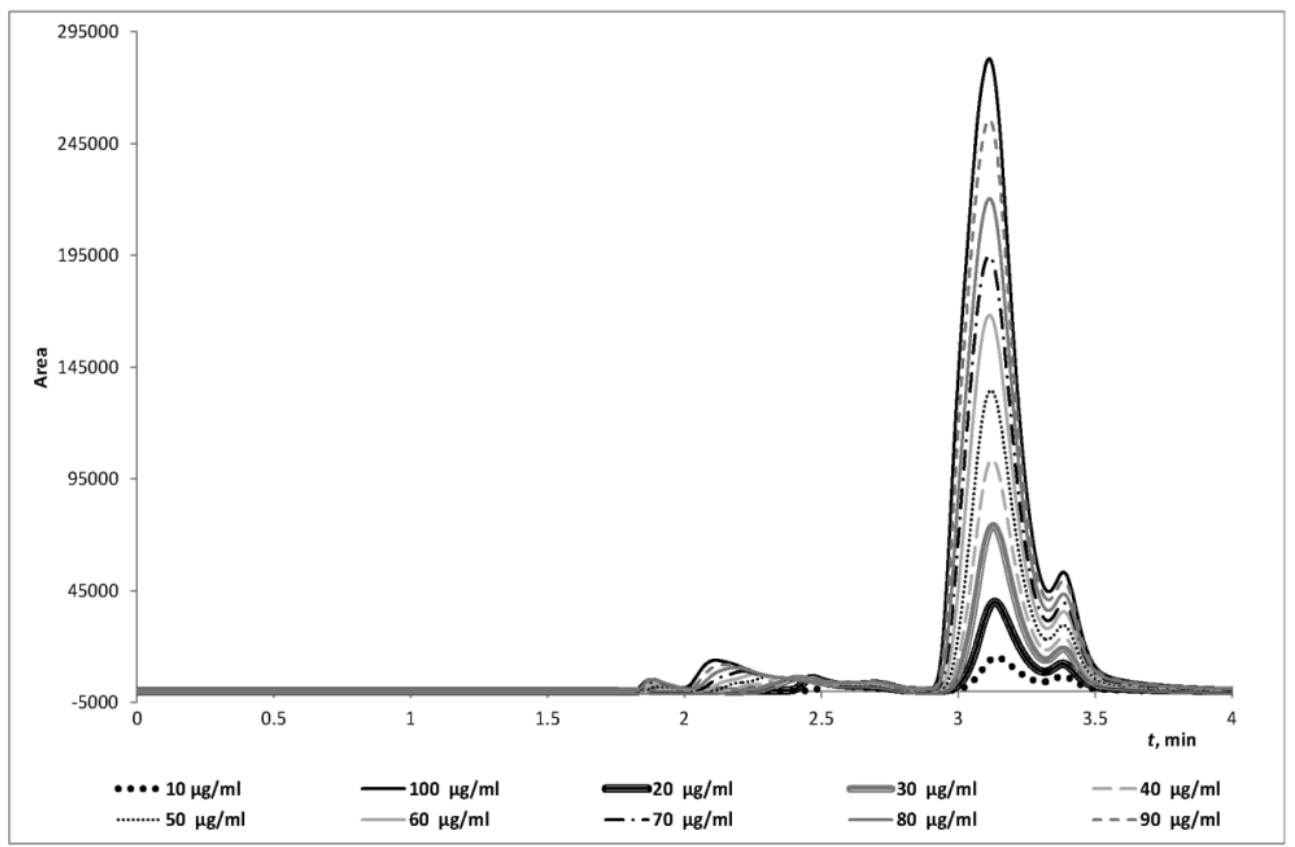

Figure 5. HPLC of $N$-isonicotynoyl- $N$ '-(3-fluorobenzal)hydrazone detection at $\lambda 300 \mathrm{~nm}$, mobile phase: ACN/phosphate buffer (60:40, v/v), pH 2.4 .

The obtained HPLC chromatograms did not contain any interference peaks, which could influence the quantitative results. However, the peaks obtained by this method were split, which could be due to the presence of E/Z-isomer of SH2 (Fig. 6), and consequently a sign for better separation of the main product. Besides, the base line is straight and stable with lower signal noise.

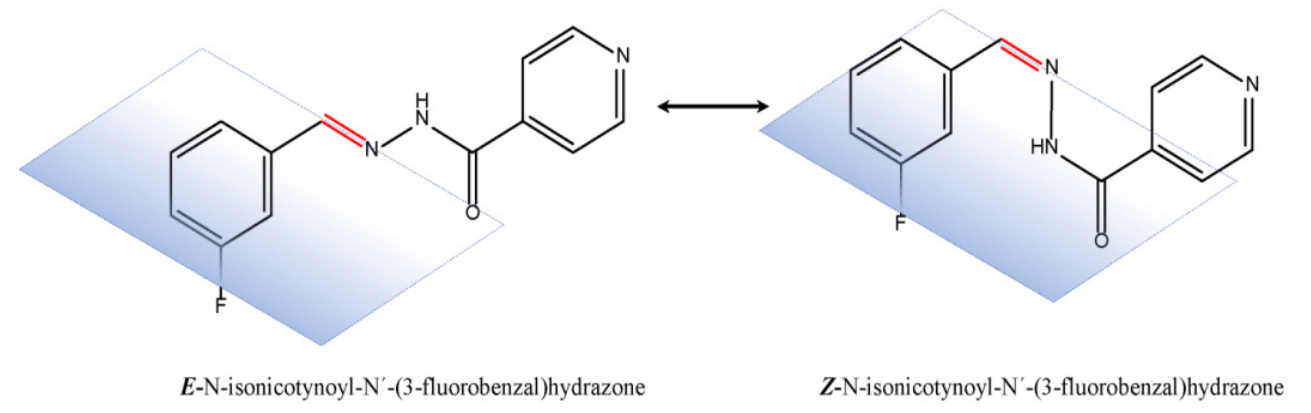

Figure 6. Structural formulas of E/Z-isomers of SH2. 
The obtained standard calibration curve at these HPLC conditions is presented in Fig. 7.

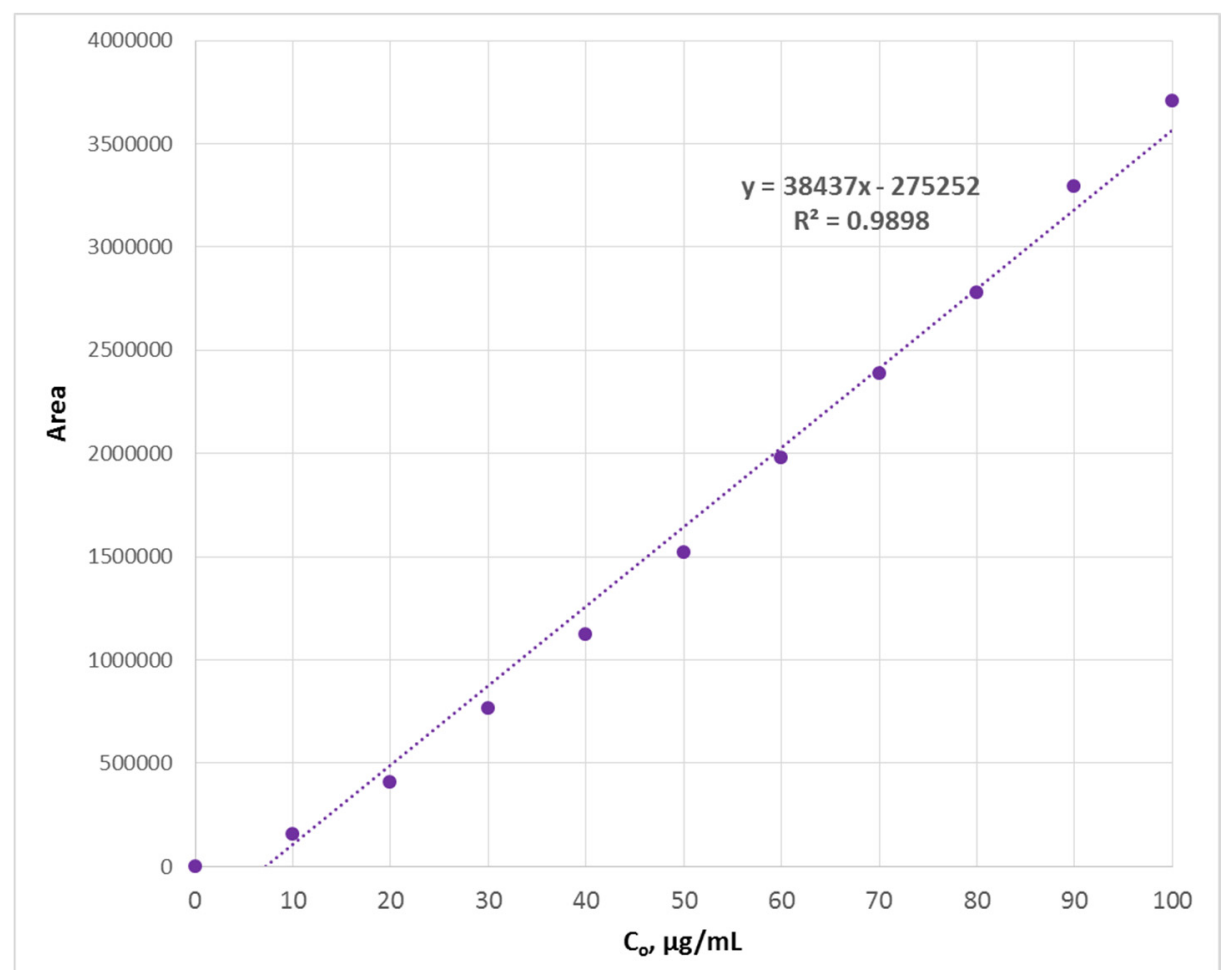

Figure 7. HPLC calibration curve of N-isonicotynoyl-N'-(3-fluorobenzal)hydrazone at $\lambda 290 \mathrm{~nm}$ (mobile phase: $\mathrm{ACN} / \mathrm{H}_{3} \mathrm{PO}_{4}(60: 40, \mathrm{v} / \mathrm{v})$.

The correlation regression coefficient in this case was higher $\left(R^{2}\right.$ 0.9898) when compared to that obtained by HPLC Method I and lower than the value of the UVIVIS method. The linear equation (Eq. 3) characterized with a greater slope $a=38437$ and with a negative intercept $b=-275252$.

$$
y=38437 . x-275252
$$

\section{Accuracy and effectiveness of the applied analytical methods}

To assess the applicability of the three methods investigated, the RSD, LOD and LOQ were determined based on the obtained in the recent study experimental data. 
The values of LOD and LOQ were estimated according to the guidelines of the International Conference on Harmonization of Technical Requirements for Registration of Pharmaceuticals for Human Use (ICH) based on the standard deviation of the response and the slope of the calibration curve of the analyte [15]. The values of these parameters are presented in Table 1.

Table 1. Values of $R S D \%, L O D(\mu \mathrm{g} / \mathrm{mL})$ and $L O Q(\mu \mathrm{g} / \mathrm{mL})$ for the UVIVIS and HPLC methods

\begin{tabular}{llll}
\hline Method & $\mathbf{R S D}, \boldsymbol{\%}$ & $\mathbf{L O D}, \boldsymbol{\mu g} / \mathbf{m L}$ & $\mathbf{L O Q}, \boldsymbol{\mu g} / \mathbf{m L}$ \\
\hline UVNIS Method & $\mathbf{2 . 1 2}$ & 3.31 & 10.04 \\
HPLC Method I & 3.77 & 0.682 & 2.54 \\
HPLC Method II & 3.50 & $\mathbf{0 . 3 4 6}$ & $\mathbf{1 . 0 5}$ \\
\hline
\end{tabular}

The comparative analyses of the obtained experimental results revealed that the developed and applied UVIVIS spectrophotometric method characterized with the highest correlation coefficient and lowest $R S D$ value. However, the determined $L O D$ and $L O Q$ values were the highest. Thus, it could be suitable for analyses of aqueous samples with higher heterocyclic compound concentrations. According to the spectra presented in Fig. 1 solutions with $\mathrm{SH} 2$ concentrations lower than $10 \mu \mathrm{g} / \mathrm{mL}$ characterized with not wellresolved spectral peaks, i.e. the accuracy of the method below this limit would be unsatisfactory. However, the main advantage of this method is its costeffectiveness and rapidity.

Regarding the developed HPLC methodologies, and based on the data from Table 1, it could be concluded that undoubtedly HPLC Method II displayed the highest accuracy and efficiency as the determined $R S D, L O D$ and $L O Q$ values were the lowest. The comparative estimation of the HPLC spectral data of $\mathrm{SH} 2$ obtained by both liquid-chromatographic methods (Fig. 2, 3) revealed that the spectral peaks of Method II characterized with approximately 3 times greater area. Besides, they were significantly more pronounced in the entire tested concentration range. The presence of a secondary small peak at the bottom of the main one could be attributed to the detection of an isomer molecule, which is a sign for better separation of the biologically active compound(s), as well as for the higher accuracy of the method. The proportional increase of the secondary peak area could be used for the quantitative analyses of the detected isomer by a proper modification of the current analytical method in future investigations of the present scientific team. The latter observations are supported by the significantly lower $L O D$ and $L O Q$ values. Another main advantage of Method II is the registered short retention time. 


\section{CONCLUSIONS}

A RP-HPLC-PDA analytical methodology appropriate for the quantitative determination of the novel drug candidate $\mathrm{N}$-isonicotynoyl- $\mathrm{N}^{\prime}$ (3-fluorobenzal)hydrazone in aqueous phase, and the qualitative analyses of its isomer was developed in the present study. Desirable chromatographic separation was achieved on a $\mathrm{C}_{18}$ column employing a mixture of $\mathrm{ACN}$ and $0.1 \mathrm{M} \mathrm{H}_{3} \mathrm{PO}_{4}(60: 40 ; \mathrm{v} / \mathrm{v})$ as the mobile phase. The obtained HPLC chromatograms were well pronounced and did not contain any interference peaks, which could influence the quantitative results. The applied method offered short analysis time (3.1 min), high precision (RSD $3.5 \%)$ and high linearity $\left(R^{2} 0.9898\right)$. It characterized with satisfactory $L O D$ and $L O Q$ values. The simple and rapid method developed enhances the capabilities for the accurate and selective determination of $\mathrm{SH} 2$ in concentrations even below $10 \mu \mathrm{g} / \mathrm{mL}$ in aqueous phase, as well as detection of its $E / Z$ isomer.

\section{EXPERIMENTAL SECTION}

\section{Chemicals}

Isonicotynoylhydrazide (Bristol-Myers Squibb Co.), 3-fluorobenzaldehyde, acetonitrile (ACN, $\geq 99.8 \%$ ), orthophosphoric acid $\left(\mathrm{H}_{3} \mathrm{PO}_{4} 85 \%\right)$, methanol ( $\geq 99.9 \%$ ), ethanol (p.a. $\geq 99.8 \%$ ), and $\mathrm{Na}_{2} \mathrm{HPO}_{4} .2 \mathrm{H}_{2} \mathrm{O}$ (HPLC, $\geq 98.5 \%$ ) HPLC grade, were obtained from Sigma-Aldrich.

\section{Synthesis of $\mathbf{N}$-isonicotynoyl-N'-(3-fluorobenzal)hydrazone SH2}

$\mathrm{N}$-isonicotynoyl- $\mathrm{N}^{\prime}$-(3-fluorobenzal)hydrazone was synthesized according to our previously reported procedure $[8,9]$. In brief: isonicotynoylhydrazide $2.74 \mathrm{~g}(0.02 \mathrm{~mol})$ was mixed with 3-fluorobenzaldehyde in $50 \mathrm{~mL}$ absolute ethanol. The reaction mixture was heated to reflux for 4 hours. After cooling of the filtrate, white crystals crystallized, which after recrystallization from absolute ethanol had a melting temperature of $201.5-203^{\circ} \mathrm{C}$. The yield was $86 \%$.

Standard stock solutions $(100 \mu \mathrm{g} / \mathrm{mL})$ were prepared by dissolving the appropriate amount of $\mathrm{N}$-isonicotynoyl-N'-(3-fluorobenzal)hydrazone in Milli-Q water acidified with $\mathrm{H}_{3} \mathrm{PO}_{4}$ at $p H 2.4$. Working standard solutions $(10-100 \mu \mathrm{g} / \mathrm{mL})$ were prepared daily. 


\section{Physicochemical characteristics of $\mathrm{N}$-isonicotynoyl-N'- (3-fluorobenzal)hydrazone}

The software package CS Chem 3D ultra was used to calculate the basic molecular characteristic of $\mathrm{N}$-isonicotynoyl- $\mathrm{N}^{\prime}$-(3-fluorobenzal)hydrazone. Elemental analysis and testing of the organic compound were conducted for identification and quantification of elements. The molecular formula of the compound is presented in Fig. 8.
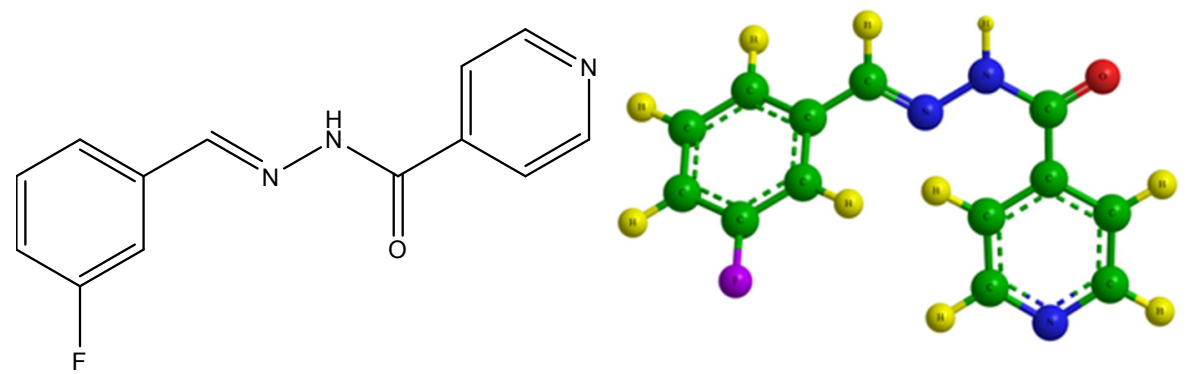

Figure 8. Molecular formula of $\mathrm{SH}$.

The physicochemical, molecular properties and elemental analyses data of $\mathrm{SH} 2$ are displayed in Table 2.

\section{UV/VIS spectrophotometric analyses}

$\mathrm{N}$-isonicotynoyl-N'-(3-fluorobenzal)hydrazone concentrations were measured with UV-VIS spectrophotometer DR 5000 Hach Lange (Germany), supplied with $10 \mathrm{~mm}$ quartz cells. All spectra were recorded in the UV region at $\lambda 250 \mathrm{~nm}$ with $2 \mathrm{~nm}$ slit width, $900 \mathrm{~nm} \mathrm{~min}{ }^{-1}$ scan speed and very high smoothing.

Table 2. Physicochemical characteristics of $\mathrm{N}$-isonicotynoyl- $\mathrm{N}^{\prime}$ -

(3-fluorobenzal)hydrazone

\begin{tabular}{cc}
\hline Molecular formula & $\mathrm{C}_{13} \mathrm{H}_{10} \mathrm{FN}_{3} \mathrm{O}$ \\
\hline UIPAC name & $\begin{array}{c}\text { 3-fluorobenzaldehyde } \\
\text { isonicotynoylhydrazone }\end{array}$ \\
\hline Molecular mass, $\mathrm{g} / \mathrm{mol}$ & 243.236 \\
\hline Molecular ovality & 1.42697 \\
\hline Connolly Accessible Area, $\AA^{2}$ & 440.753 \\
\hline
\end{tabular}




\begin{tabular}{|c|c|}
\hline Connolly Molecular Area, $\AA^{2}$ & 219.941 \\
\hline Connolly Solvent Excluded Volume, $\AA^{2}$ & 179.932 \\
\hline Mass-to-charge ratio, $\mathrm{m} / \mathrm{z}$ & $\begin{array}{c}243.08(100.0 \%), 244.08(15.2 \%), \\
245.09(1.1 \%)\end{array}$ \\
\hline \multicolumn{2}{|c|}{ Elemental analyses: } \\
\hline $\begin{array}{l}\text { calculated (\%): } \\
\text { determined }(\%) \text { : }\end{array}$ & $\begin{array}{l}\text { N } 17.28 \\
\text { N } 17.57\end{array}$ \\
\hline
\end{tabular}

\section{HPLC system and conditions}

RP-HPLC system comprising of a Hypersil BDS $C_{18}(5 \mu \mathrm{M}, 4.6 x$ $150 \mathrm{~mm}$ ) column, Surveyor LC Pump Plus, PDA detector, and Surveyor Autosampler Plus (Thermo Fisher Scientific) was used. The tested mobile phases consisted of a mixture of $A C N / 0.1 \mathrm{M} \mathrm{H}_{3} \mathrm{PO}_{4}(60: 40, \mathrm{v} / \mathrm{v})$ and phosphate buffer $(p H 5) /$ methanol $(90: 10, v / v)$. The samples were monitored at $290 \mathrm{~nm}$ and $254 \mathrm{~nm}$, respectively. The buffer $\mathrm{pH}$ was adjusted to 2.4 with $\mathrm{H}_{3} \mathrm{PO}_{4}$. The volume injected into the HPLC column was $20 \mu \mathrm{l}$.

All UVIVIS spectrophotometric and HPLC analyses were made in triplicate.

The experimental data was analyzed by regression analyses and determination of the corresponding correlation coefficients $\left(R^{2}\right)$ and relative standard deviation $(R S D, \%)$.

The efficiency and accuracy of the developed UVIVIS and HPLC methods was estimated based on the calculated limit of detection $(L O D)$ and limit of quantification (LOQ).

\section{ACKNOWLEDGMENTS}

The study was supported financially by Scientific Project No. 14-15 VMF, Faculty of Veterinary Medicine, Trakia University, Stara Zagora, Bulgaria. 


\section{REFERENCES}

1. S. Ellis, D.S. Kalinowski, L. Leotta, M.L.H. Huang, P. Jelfs, V. Sintchenko, D.R. Richardson, J.A. Triccas, Mol. Pharmacol., 2014, 85, 269.

2. C.E. Cade, A.C. Dlouhy, K.F. Medzihradszky, S.P. Salas-Castillo, R.A. Ghiladi, Protein Sci., 2010, 19 (3), 458.

3. D. Sriram, P. Yogeeswari, K. Madhu, Bioorganic \& Medicinal Chemistry Letters, 2005, 15, 4502.

4. B. Moksharagni, K.D. Kumar, S. Chandrasekhar, K.H. Reddy, Int. J. Pharm. Bio. Sci., 2015, 6 (3), 11.

5. S. Rollas, S.G. Küçükgüzel, Molecules, 2007, 12, 1910.

6. M. Hermes-Lima, M. S. Gonçalves, R. G. Andrade Jr., Molec. Cell. Biochem., 2001, 228, 73.

7. A.Q. Mauricioa, G.K.B. Lopes, C.S. Gomes, R.G. Oliveira, A. Alonso, M. Hermes-Lima, Biochimica et Biophysica Acta, 2003, 1620, 15.

8. S. Varbanova, N. Georgieva, Veterinary Science, 1993, 27, 81.

9. N. Georgieva, V. Gadjeva, Biochemistry (Moscow), 2002, 67, 588.

10. E. Potuckova, K. Hruskova, J. Bures, P. Kovarıkova, I.A. Spirkova, PLoS ONE, 2014, 9 (11), 112059.

11. A. Córdoba-Díaz, M. Córdoba-Díaz, M., B. Elorza, Spectroscopy, 2009, 23, 201.

12. N. Georgieva, Z. Yaneva, Cogent Chemistry (2015), 1, 1-16.

13. Z. Yaneva, N. Georgieva, V. Koinarski, D. Petrova, Trakia Journal of Sciences, 13, Suppl. 2, 309-314, 2015.

14. N. Georgieva, Z. Yaneva, G. Nikolova, S. Simova, Advances in Bioscience and Biotechnology, 2012, 3(7A), 1.

15. International Conference on Harmonization of Technical Requirements for Registration of Pharmaceuticals for Human Use, ICH Harmonized Tripartite Guideline, Validation of Analytical Procedures: Text and methodology, Q2 (R1), p. 1-13 (2005). 
